NOTICE: This is the author's version of a work that was accepted for publication in Thin Solid Films. Changes resulting from the publishing process, such as peer review, editing, corrections, structural formatting, and other quality control mechanisms may not be reflected in this document. Changes may have been made to this work since it was submitted for publication. A definitive version was subsequently published in Thin Solid Films [519, 10, 2011] DOI http://dx.doi.org/10.1016/j.tsf.2011.01.260 


\section{Accepted Manuscript}

A modified layer removal method for residual stress measurement in electrodeposited nickel films

L.M. Jiang, J. Peng, Y.G. Liao, Y.C. Zhou, J. Liang, H.X. Hao, C. Lu

PII: S0040-6090(11)00323-3

DOI: doi: 10.1016/j.tsf.2011.01.260

Reference: $\quad$ TSF 28792

To appear in: $\quad$ Thin Solid Films

Received date: $\quad 26$ November 2009

Revised date: $\quad 28$ October 2010

Accepted date: 16 January 2011

Please cite this article as: L.M. Jiang, J. Peng, Y.G. Liao, Y.C. Zhou, J. Liang, H.X. Hao, C. Lu, A modified layer removal method for residual stress measurement in electrodeposited nickel films, Thin Solid Films (2011), doi: 10.1016/j.tsf.2011.01.260

This is a PDF file of an unedited manuscript that has been accepted for publication. As a service to our customers we are providing this early version of the manuscript. The manuscript will undergo copyediting, typesetting, and review of the resulting proof before it is published in its final form. Please note that during the production process errors may be discovered which could affect the content, and all legal disclaimers that apply to the journal pertain. 


\title{
A modified layer removal method for residual stress measurement in electrodeposited nickel films
}

\author{
L.M. Jiang ${ }^{\text {a,b }}$, J. Peng ${ }^{\text {a }}$, Y.G. Liao ${ }^{\text {c }}$, Y.C. Zhou ${ }^{\text {a,* }}$, J. Liang ${ }^{\text {a }}$, H.X. Hao ${ }^{\text {a }}$, C. Lu ${ }^{\text {d }}$ \\ ${ }^{a}$ Key Laboratory of Low Dimensional Materials and Application Technology of \\ Ministry of Education, Xiangtan University, Hunan 411105, China \\ ${ }^{b}$ College of Packaging and Material Engineering, Hunan University of Technology, \\ Hunan 412007, China \\ ${ }^{c}$ Faculty of Mathematics and Physics, University of South China, Hunan 421001, \\ China \\ ${ }^{\mathrm{d}}$ Department of Mechanical Engineering, Curtin University, Western Australia 6845, \\ Australia
}

\begin{abstract}
Combining the traditional layer removal method with a cantilever beam model, a modified layer removal method is developed and used to measure residual stress in single and multi-layer electrodeposited nickel films with thickness of $2.5 \mu \mathrm{m}$. The out-of-plane displacement of the free tip of a cantilever beam is measured by the digital speckle correlation method. The results show that residual stress in a single semimat nickel film is compressive, while in a multi-layer system composed of dark, semimat and holophote nickel, residual stress in the surface layer is tensile. Residual stress decreases gradually with the increase of etching depths of single and multi-layer films. These findings are in qualitative agreement with nanoindentation tests, which confirms the reliability of the modified layer removal method.
\end{abstract}

Keywords: Modified layer removal method; Nickel film; Residual stress; Nanoindentation

* Corresponding author.Tel.: +86 731 58293586; fax: +86 731 58292468; E-mail address: zhouyc@xtu.edu.cn 


\section{Introduction}

Electrodeposition films have been widely applied in decoration and protection industries due to their excellent mechanical properties such as high tensile strength and elongation, good corrosion resistance and temperature tolerance [1-3]. Thus, a better understanding of factors that affect the service life of electrodeposition films is of great importance. As is well known, residual stress exists widely owing to the lattice mismatch or non-uniform plastic deformation in a film/substrate system. It may induce failure of manufactured products by fatigue or environmental degradation, alter performance of these products by crazing or changing in shape, and then reduce their load carrying capacities. Therefore, to predict and improve the reliability of devices consisting of electrodeposited nickle films, it is necessary to measure residual stress in these thin films.

A lot of techniques have been developed to measure residual stress in films, which are divided into two types: non-destructive methods and locally destructive methods. The former include X-ray diffraction, neutron diffraction and magnetic or ultrasonic methods and the latter are mainly mechanical means such as hole drilling, nanoindentation and layer removal methods [4-6]. These methods have their respective advantages and limitations. For example, it is difficult for manufacturers and laboratory researchers to gain access to high-energy synchrotron X-ray and neutron diffractions. Even though the conventional X-ray diffraction is easier to access, the small penetration depth of X-ray in engineering materials limits its applicability in the case of depth resolved residual stress [7]. Here, the estimation of residual stress by using the hole-drilling method [8] relies on mechanical properties of materials. Because of its 
user-friendly feature, the layer-removal method is one of the most commonly used destructive methods. Like the hole-drilling procedure, however, the conventional layer-removal method [9] is developed for a single isotropic material that does not take into account the difference of mechanical properties of substrate and coating. To solve this problem, a modified layer-removal method for evaluating the through-thickness residual stress distribution in coated materials has been proposed [10,11]. However, due to small thickness of nickel film (with several micrometers) in an electrodeposited nickel film/substrate system, it is hard to measure the curvature of bending moment caused by the release of residual stress using the modified layer-removal method proposed by Greving et al. [10,11]. Thus, the evaluation of residual stress in an electrodeposited nickel film system is still a big challenge.

In this paper, a modified layer removal method is developed to measure residual stress in a single-layer or multi-layer electrodeposited nickel film with the thickness of $2.5 \mu \mathrm{m}$. Similar to the layer removal method [12], specimens are mounted as cantilever beams and the acid attack is restricted to a narrow transverse strip. It is assumed that residual stress is in a state of self-equilibrium; and after part of the material is taken away, the sample bends to restore balance following stress redistribution. For example, the removal of surface layer of a plate with a longitudinal stress distribution generates a bending moment. By measuring curvatures after successively eliminating layers through thickness, the initial stress distribution can be reconstructed [4,13]. Combining the traditional layer removal method with a cantilever beam model, the curvature of 
bending moment caused by the release of residual stress can be measured indirectly through the determination of out-of plane displacement of the free tip of a cantilever.

\section{Modified layer removal method}

The modified layer removal method is illustrated in Fig. 1, where the reference plane $(z=0)$ is located at the center of thickness of a sample and the force acting on the layer in the $x$-direction is denoted as $F_{x}$. For convenience, it is assumed that principal stresses coincide with the rolling $(x)$ and transverse $(y)$ directions and the electrodeposited nickel film is under a biaxial plane stress state (i.e., $\sigma_{x}=\sigma_{y}$ and $\left.\sigma_{z}=0\right)$. Because the specimen is mounted as a cantilever beam and its size in the transverse direction $(y)$ is much less than that in the rolling direction $(x)$, deformation in the transverse direction can be neglected. Thus, such a planar problem is simplified to a linear problem. Further, the evaluation of residual stress from beam bending is similar to but a little more easier to do than those from evolution processes reported [9-11,14-17]. According to the generalized Hooke's law, the relationships between stress and strain are:

$$
\varepsilon_{x}=\frac{1}{E}\left(\sigma_{x}-v \sigma_{y}\right)=\frac{\sigma_{x}}{E}(1-v), \varepsilon_{y}=\frac{1}{E}\left(\sigma_{y}-v \sigma_{x}\right)=\frac{\sigma_{x}}{E}(1-v)
$$

where $E$ is Young's modulus, $v$ is Poisson's ratio, $\varepsilon_{x}$ and $\varepsilon_{y}$ are plane strains in the $x$ and $y$ directions, and $\sigma_{x}$ and $\sigma_{y}$ are the corresponding plane stresses, respectively. Compared to the remainder, the removal piece is so small that the change of strain $\varepsilon_{x}$ can be approximated as a linear function of depth $z$ [11]:

$$
\varepsilon_{x}(z)=\varepsilon_{x 0}+K z
$$


where $\varepsilon_{x 0}$ is the strain of the reference plane $(z=0)$ and $K$ is the curvature of the sample.

The stress $\sigma_{x}$ in Eq. (1) can be rewritten as

$$
\sigma_{x}(z)=\frac{E}{(1-v)} \varepsilon_{x}(z)
$$

and then, the force $F_{x}$ and the moment $M_{y}$ are given by

$$
\begin{aligned}
& F_{x}=\int_{\frac{H}{2}}^{\frac{H}{2}-l} \sigma_{x}(z) d z=\int_{\frac{H}{2}}^{\frac{H}{2}-h} \sigma_{x s}(z) d z+\int_{\frac{H}{2}-h}^{H}-l=\sigma_{x c}(z) d z \\
& M_{y}=\int_{\frac{H}{2}}^{H}-l \quad \sigma_{x}(z)\left(z+\frac{l}{2}\right) d z=\int_{\frac{H}{2}}^{H}-h \quad \sigma_{x s}(z)\left(z+\frac{l}{2}\right) d z+\int_{\frac{H}{2}-h}^{H}-l \quad \sigma_{x c}(z)\left(z+\frac{l}{2}\right) d z
\end{aligned}
$$

where subscripts $s$ and $c$ denote substrate and film, respectively.

Substituting Eqs. (2) and (3) into Eqs. (4) and (5), we have

$$
\left(\begin{array}{l}
F_{x} \\
M_{y}
\end{array}\right)=\left[\begin{array}{ll}
A_{11} & A_{12} \\
A_{21} & A_{22}
\end{array}\right]\left(\begin{array}{l}
\varepsilon_{x 0} \\
K
\end{array}\right)
$$

where

$$
\begin{gathered}
A_{11}=\frac{H-h}{1-v_{s}} E_{s}+\frac{h-l}{1-v_{c}} E_{c} \\
A_{12}=\frac{1}{2}\left\{\frac{E_{s}}{1-v_{s}}\left(h^{2}-H h\right)+\frac{E_{c}}{1-v_{c}}\left[\left(\frac{H}{2}-l\right)^{2}-\left(\frac{H}{2}-h\right)^{2}\right]\right\} \\
A_{21}=\frac{l}{2} A_{11}+A_{12} \\
A_{22}=\frac{1}{3}\left\{\frac{E_{s}}{1-v_{s}}\left[\left(\frac{H}{2}-h\right)^{3}-\left(\frac{H}{2}\right)^{3}\right]+\frac{E_{c}}{1-v_{c}}\left[\left(\frac{H}{2}-l\right)^{3}-\left(\frac{H}{2}-h\right)^{3}\right]\right\}+\frac{l}{2} A_{12}
\end{gathered}
$$

The resultant force and moment acting on the remained part of the sample are related to residual stress in electrodeposited films by: 


$$
\left(\begin{array}{l}
F_{x} \\
M_{y}
\end{array}\right)=-\left(\begin{array}{l}
\sigma_{x}(z) l \\
\frac{H}{2} l \sigma_{x}(z)
\end{array}\right)
$$

Then, the combination of Eq. (6) with Eq. (7) gives

$$
\left[\begin{array}{ll}
A_{11} & A_{12} \\
A_{21} & A_{22}
\end{array}\right]\left(\begin{array}{l}
\varepsilon_{x 0} \\
K
\end{array}\right)=-\left(\begin{array}{l}
\sigma_{x}(z) l \\
\frac{H}{2} l \sigma_{x}(z)
\end{array}\right)
$$

For an electrodeposited nickel film/low carbon steel system, material properties such as Young's modulus $E$ and Poisson's ratio $v$ and geometric parameters such as the thickness $H$ of sample and the thickness $h$ of film can be directly measured. In addition, the thickness $l$ of a layer removed can be indirectly determined by measuring remained parts of the film after successively eliminating layers through thickness. Thus, the coefficient matrix on the left side of Eq. (8) is a constant matrix, and only three parameters, $\sigma_{x}(z), \varepsilon_{x 0}$ and $K$, are unknown. In the proposed modified layer removal method, the curvature of bending moment $K$ caused by the release of residual stress can be measured indirectly through the out-of plane displacement of specimen's free tip. Then, the residual stress $\sigma_{x}(z)$ in the film is obtained through solving Eq. (8).

\section{Experimental}

\subsection{Preparation of samples}

A nickel film with thickness of $2.5 \mu \mathrm{m}$ is electrodeposited on a steel sheet of thickness of $0.275 \mathrm{~mm}$. The film is electrodeposited with nickel sulphate electrolyte which is composed of $250 \mathrm{~g} \mathrm{NiSO} 4 \cdot 6 \mathrm{H}_{2} \mathrm{O}, 50 \mathrm{~g} \mathrm{NiCl}_{2} \cdot 6 \mathrm{H}_{2} \mathrm{O}$, and $35 \mathrm{~g} \mathrm{H}_{3} \mathrm{BO}_{3}$ per liter. Pure nickel is used as anode. The $\mathrm{pH}$ value is adjusted with sulfuric acid to 4.0 at $42^{\circ} \mathrm{C}$. A conventional rotating disc electrode is used for electrodeposition. Before 
electroplating, pretreatment is necessary to get rid of impurities. Here, Young's moduli of substrate and film are $E_{s}=220 \mathrm{GPa}$ and $E_{c}=200 \mathrm{GPa}$, Poisson's ratios of substrate and film are $v_{s}=v_{c}=0.3$, respectively. In experiments, the size of a sample is $100 \mathrm{~mm}$ in the $x$-axis direction and $20 \mathrm{~mm}$ in the $y$-axis direction.

\subsection{Chemical etching}

The chemical etching method is adopted for removing the surface layer of a sample, which can avoid introducing significant additional stress and allow the removal of very thin layers. The surface layer is removed slowly by dilute nitric acid with the concentration of $15 \%$. The samples are clamped as cantilever beams. Before etching, the surface is covered with epoxy resin, except for a transversal strip of $3 \mathrm{~mm}$ width in the $y$-axis direction. One edge of the strip is $57 \mathrm{~mm}$ away from the free end, which is about $40 \mathrm{~mm}$ from the other edge of the strip to the clamped end, as shown in Fig. 1. Because the removal area is very small, it is supposed that bending only happens in the etching area and the remainder moves rigidly.

\subsection{Calculation of curvature}

The formula used to calculate the curvature $K$ of a cantilever beam can be expressed as

$$
K=\frac{1}{R}=\frac{\phi}{\omega} \approx \frac{\tan \phi}{\omega}
$$

where $R$ is the curvature radius, $\omega=3 \mathrm{~mm}$ is the width of the bending area, and $\phi$ is the bending angle (see Fig. 1). Because the bending angle is very small, $\phi \approx \tan \phi$. Here, the value of $\tan \phi$ can be obtained by 


$$
\tan \phi=\frac{d}{x}
$$

where $d$ is the out-of plane displacement of a selected point of the sample after layer removal, and $x$ is the abscissa of the selected point. The digital speckle correlation method is usually used to measure in-plane displacement $[18,19]$, however, based on the optical arrangement illustrated in Fig. 1, the out-of plane displacement of the free end can be measured indirectly through the in-plane displacement. As illustrated in Fig. 1, it is obvious that the triangle $\triangle \mathrm{ABO}$ is similar to the triangle $\triangle \mathrm{MNO}$, that is

$$
\frac{d(x, y)}{e}=\frac{D-d(x, y)}{T}
$$

Then, we have

$$
e=\frac{T d(x, y)}{D-d(x, y)}
$$

where $T$ and $D$ are constants for a fixed optical measure system. Due to $d(x, y)<<D$, Eq. (11) can be reduced as

$$
e=\frac{T}{D} d(x, y)
$$

or

$$
d(x, y)=\frac{D}{T} e
$$

Once the value of the in-plane displacement $e$ is known, the out-of plane displacement $d(x, y)$ can be calculated. Here, $e$ can be determined through the measured value of $e^{\prime}$ following the similar principle of triangles, that is

$$
e=\frac{e^{\prime}}{C} D
$$

where $C$ is also a constant for a fixed optical measure system. The apparatus used to 
measure the out-of plane displacement of a cantilever beam is illustrated in Fig. 2. Finally, the curvature $K$ can be calculated by the combination of Eqs. (9)-(13).

\section{Results and discussion}

Nine samples deposited with semimat nickel film are measured by the modified layer removal method. To verify the proposed method, nanoindentation test is also carried out, which is one of the most flexible tools for measuring local and volume-averaged residual stresses along with properties in graded materials such as electrodeposited semimat nickel films. According to the methodology developed by Suresh [20] for estimating residual stresses by instrumented sharp indentation, tensile residual stress in a sample can be estimated by:

$$
\sigma^{R}=P_{a v}\left(e \frac{A_{0}}{A}-1\right)
$$

while compressive residual stress can be estimated by:

$$
\sigma^{R}=\frac{P_{a v e}}{\sin \alpha}\left(1-\frac{A_{0}}{A}\right)
$$

where $\alpha=\pi / 2-\gamma$, with $2 \gamma$ being the included angle of the indenter tip, $P_{a v e}$ is the average contact pressure (or hardness), and $A_{0}$ and $A$ are the projected contact areas of virgin material and sample with residual stress, respectively. Figure 3 exhibits typical indentation load-depth curves for different indentation depths.

The comparison of the proposed modified layer removal method and indentation is shown in Fig. 4. It is obvious that residual stresses measured by these two methods are compressive and decrease gradually with the increase of etching (or indentation depth). This is induced by the mismatch between nickel film and substrate because the crystal 
lattice constant of semimat nickel is larger than that of carbon steel. Another possible explanation is that, because the melting-point of $\mathrm{Ni}(1726 \mathrm{~K})$ is lower than that of $\mathrm{Fe}$ (1808 K), Ni film behaves as a high-mobility metal during its growth on Fe substrate. It was reported that compressive stress is developed in polycrystalline high-mobility Volmer-Weber films [21]. Although there is a same changing tendency, it is worth noting that the difference of residual stresses obtained by the two methods is obvious when etching (or indentation) depth is low, and as the increase of etching (or indentation) depth, the difference decreases. This is due to the indentation size effect that leads to a much larger measured hardness during nanoindentation, especially when indentation depth is in the range of 100-1000 nm. According to Eq. (14), residual stress is directly proportional to hardness. Thus, the residual stress measured by nanoindentation is much larger than that measured by the modified layer removal method when indentation is shallow. Based on the model proposed by Nix and Gao [22], the indentation size effect can be eliminated by using the following relationship

$$
P_{a v e}=P_{a v e}^{\prime} \sqrt{1+\frac{h^{*}}{h}}
$$

where $P_{\text {ave }}{ }^{\prime}$ is hardness without size effect, $h^{*}$ is a characteristic length related to $P_{\text {ave }}{ }^{\prime}$, $h$ is indentation depth. Residual stresses after eliminating the size effect are also plotted in Fig. 4. It is easy to see that the results obtained from the proposed modified layer removal method are closer to indentation tests without size effect. However, there is still some degree of difference, which is due to the substrate effect when indentation depth is deeper than $1 \mu \mathrm{m}$. Therefore, the validity of the modified layer removal 
method is confirmed in a qualitative sense.

Further, the modified layer removal method is used to measure residual stress in multi-layer films such as a three-layer nickel film with different grain sizes deposited on carbon steel substrate. From substrate to surface, the three layers are dark nickel, semimat nickel and holophote nickel, respectively. The whole film thickness is $2.5 \mu \mathrm{m}$. The scanning electron microscope images of the three nickel films are shown in Fig. 5. It is observed that electrodeposited nickel films grow by the Volmer-Weber mode [21] and grain sizes of dark and semimat nickel films are bigger than that of holophote nickel film. The effect of etching depth on residual stress is shown in Fig. 6. The residual stress in this multi-layer film system is tensile, which decreases with the increase of corrupt depth. Due to the difference of growing conditions, the mobility of holophote nickel film is lower than dark and semimat nickel films, which induces tensile stresses in holophote nickel film and small grain sizes. With the increase of etching depth, the mobility of atoms and grain size increase but the residual tensile stress decreases. This is consistent with the available results [21].

\section{Conclusions}

A modified layer removal method to measure residual stress in monolayer or multi-layer thin films boned on substrate has been proposed. The digital speckle correlation method was used to measure the out-of plane displacement of the cantilever beam produced by chemical etching along a narrow strip on specimens. Residual stresses in monolayer and multi-layer electrodeposited nickel films with thickness of 2.5 
$\mu \mathrm{m}$ were measured. It is shown that: (a) residual stress in a single semimat nickel film is compressive and its value decreases gradually with increase of etching depth, which is in qualitative agreement with experimental results obtained by nanoindentation; and (b) in a dark, semimat and holophote nickel multi-layer system, residual stress in surface layer is tensile but its value decreases gradually with increase of etching depth.

\section{Acknowledgments}

This work has been supported by the National Natural Science Foundation of China (Grant Nos. 50531060, 10525211 and 10828205), the Natural Science Foundation of Hunan Province for Innovation Group (09JJ7004), and the Major Scientific and Technical Innovation Project of Hunan Province (2009FJ1002). 


\section{References}

[1] Y.M. Faruq Marikar, K.I. Vasu, Electrodepos. Surf. Treat. 2 (1974) 281.

[2] Y.M. Faruq Marikar, K.I. Vasu, Electrodepos. Surf. Treat. 2 (1974) 295.

[3] J.C. Puippe, N. Ibl, Plat. Surf. Finish. 67 (1980) 68.

[4] J. Lu, Society for Experimental Mechanics, Handbook of measurement of residual stresses, Lilburn, GA: Fairmont Press, 1996.

[5] F.A. Kandil, J.D. Lord, A.T. Fry, P.V. Grant, A review of residual stress measurement methods-a guide to technique selection, Report MATC (A) 04, National Physical Laboratory, UK, 2001.

[6] Y. Pauleau, Vacuum 61 (2001) 175.

[7] F. Yang, J.Q. Jiang, F. Fang, Y. Wang, C. Ma, Mater. Sci. Eng. A 486 (2008) 455.

[8] Measurements Group, Measurement of residual stresses by the hole-drilling strain-gage method, Tech Note TN-503-3, Raleigh, NC, 1988.

[9] R.G. Treuting, W.T. Read, J. Appl. Phys. 22 (1951) 130.

[10] D.J. Greving, J.R. Shadiey, E.F. Rybbicki, J. Therm. Spray Technol. 3 (1994) 371.

[11] D.J. Greving, E.F. Rybbicki, J.R. Shadiey, J. Therm. Spray Technol. 3 (1994) 379.

[12] E. Bendek, I. Lira, M. Francois, C. Vial, Mech. Sci. 48 (2006) 1429.

[13] H.W. Walton, In: G. Totten, M. Howes, T. Inoue (Eds), Deflection methods to estimate residual stress, Handbook of residual stress and deformation of steel, ASM International, 2002, p. 89.

[14] G. Stoney, Proc. Roy. Soc. (London) A82 (1909) 172.

[15] K. Röll, J. Appl. Phys. 47 (1976) 3224.

[16] P.M. Marcus, Surf. Sci. 366 (1996) 219.

[17] K. Dahmen, H. Ibach, D. Sander, J. Magn. Magn. Mater. 231 (2001) 74. 
[18] P. Johnson, Opt. Laser Eng. 30 (1998) 315.

[19] G.C. Jin, Z. Wu, N.K. Bao, X.F. Yao, Opt. Laser Eng. 39 (2003) 457.

[20] S. Suresh, A.E. Giannakopoulos, Acta Mater. 46 (1998) 5755.

[21] R. Koch, Surf. Coat. Technol. 204 (2010) 1973.

[22] W.D. Nix, H.J. Gao, J. Mech. Phys. Solids 46 (1998) 411. 


\section{Figure captions}

Fig. 1. Illustration of a cantilever specimen and optical pathway diagram for the measurement of residual stress, where deflection of the specimen is due to the removal of a strip with the width of $3 \mathrm{~mm}$.

Fig. 2. Illustration of the digital speckle correlation method.

Fig. 3. Typical load-depth curves for different indentation depths.

Fig. 4. Comparison of the modified layer removal method and indentation method, in which dots are experimental data and solid lines indicate the changing tendency.

Fig. 5. Scanning electron microscope images of (a) dark, (b) semimat and (c) holophote nickel films with different grain sizes.

Fig. 6. Residual stress versus etching depth in a multi-layer film, where dots are experimental data and the solid line indicates the changing tendency. 


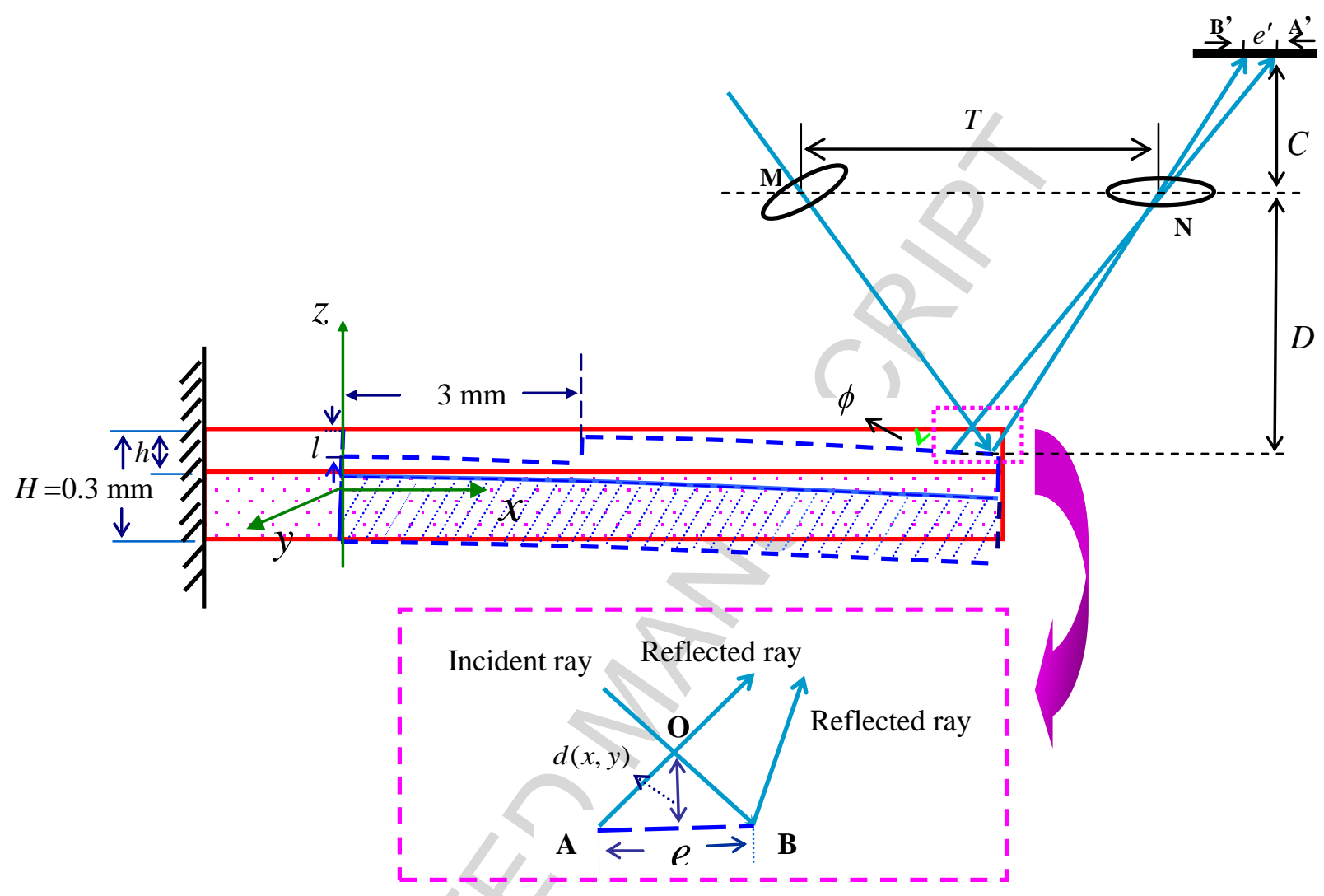

Fig. 1 


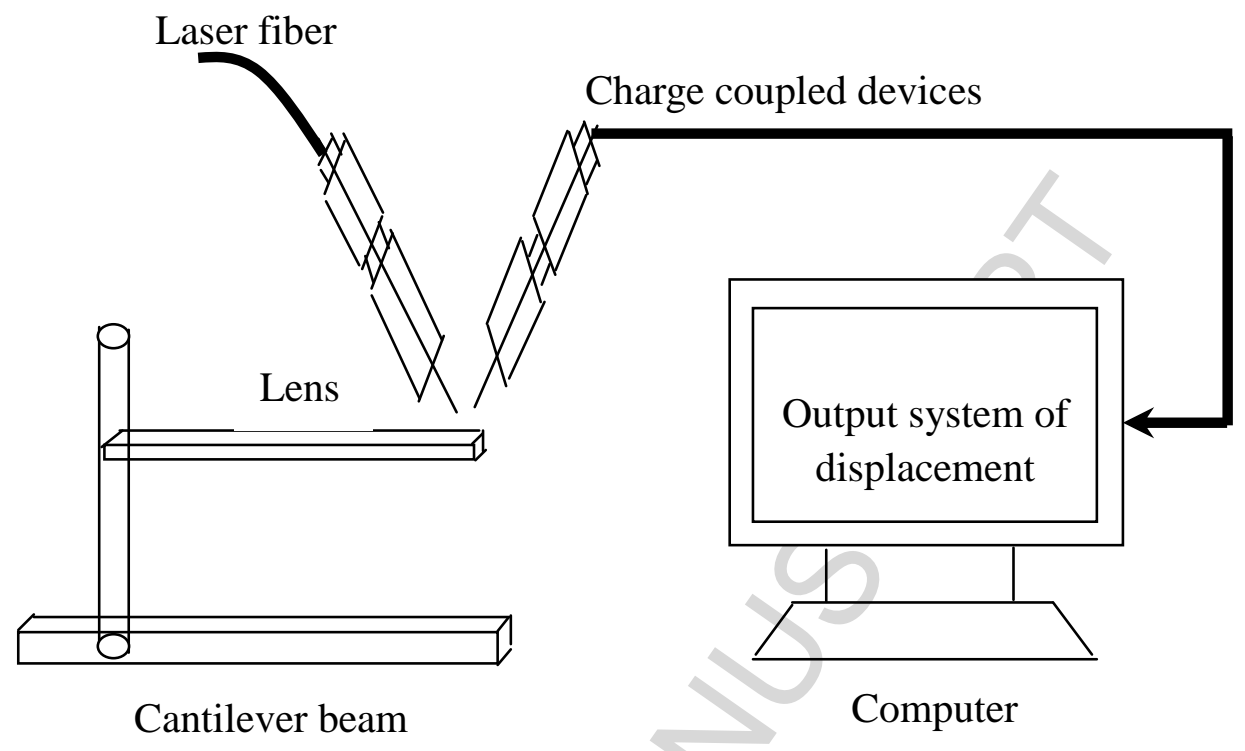

Fig. 2 


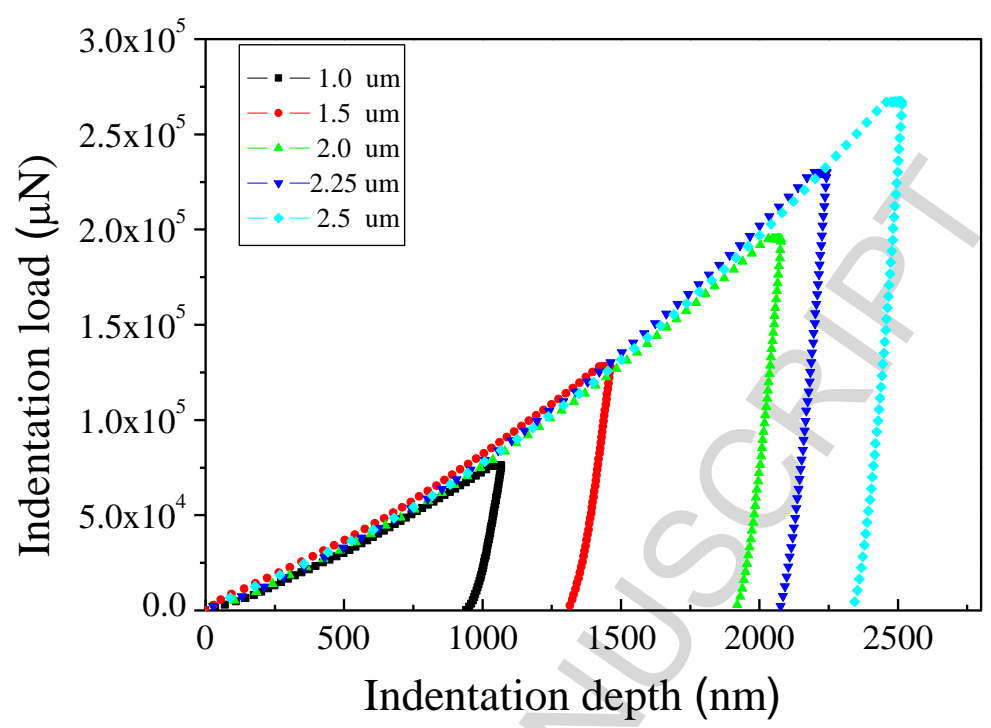

Fig. 3 


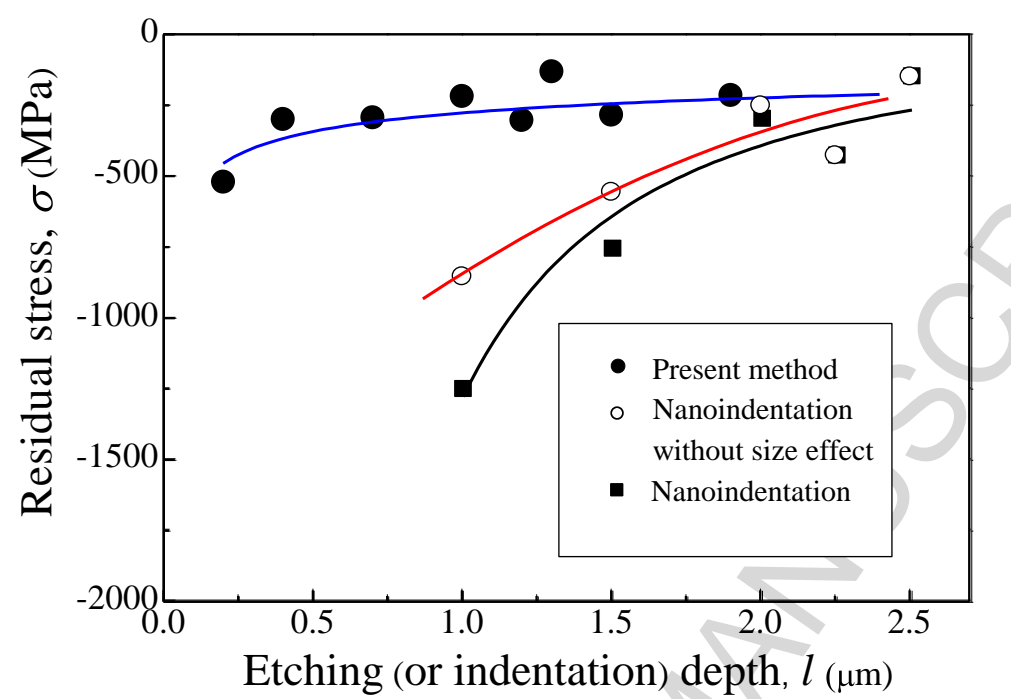

Fig. 4 

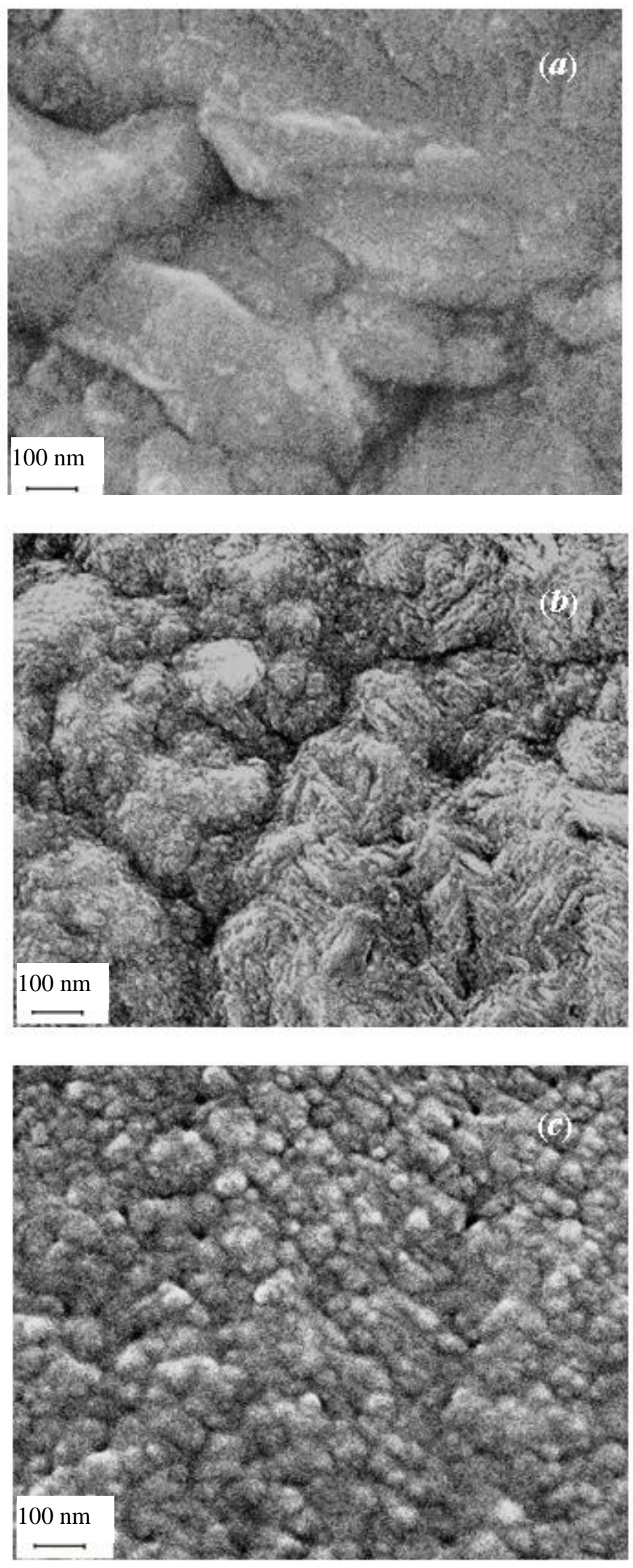

Fig. 5 


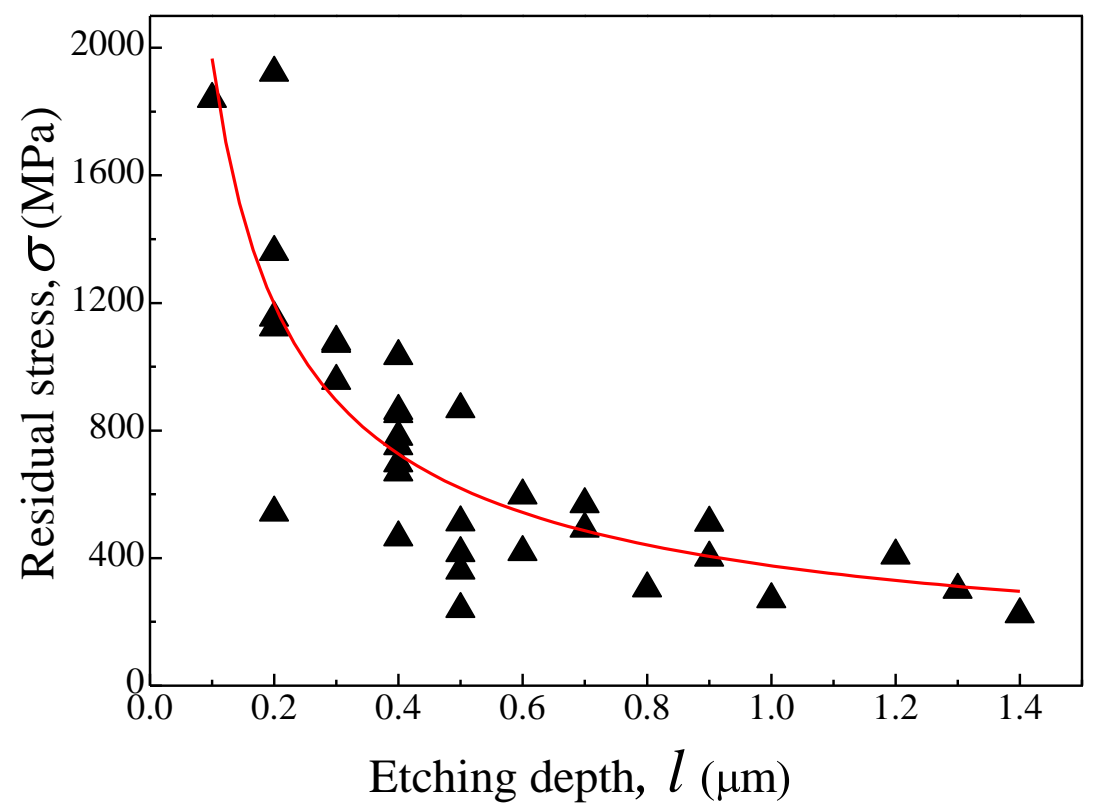

Fig. 6 